\title{
Investigating of the Microstructure and Mechanical Properties of Al-Based Composite Reinforced with Nano-Trioxide Tungsten via Accumulative Roll Bonding Process
}

\author{
Jalal Kahani Khabushan',2, Soheila Bazzaz Bonabi2 \\ ${ }^{1}$ R\&D Department, Oghab Afshan Industrial \& Manufacturing Company, Semnan, Iran \\ ${ }^{2}$ Faculty of Materials and Metallurgical Engineering, Semnan University, Semnan, Iran \\ Email:jalal_kahani@yahoo.com,jalal_kahani@students.semnan.ac.ir
}

How to cite this paper: Khabushan, J.K. and Bonabi, S.B. (2017) Investigating of the Microstructure and Mechanical Properties of Al-Based Composite Reinforced with Nano-Trioxide Tungsten via Accumulative Roll Bonding Process. Open Journal of Metal, 7, 9-23.

http://dx.doi.org/10.4236/ojmetal.2017.71002

Received: January 25, 2017

Accepted: March 26, 2017

Published: March 29, 2017

Copyright $\odot 2017$ by authors and Scientific Research Publishing Inc. This work is licensed under the Creative Commons Attribution International License (CC BY 4.0).

http://creativecommons.org/licenses/by/4.0/

\section{Open Access}

\begin{abstract}
In the present investigation, an $\mathrm{Al} / \mathrm{WO}_{3} \mathrm{p}$ metal matrix nanocomposite was fabricated by accumulative roll bonding (ARB) technique. Microstructural evaluation and mechanical properties of specimens were studied by Field Emission-Scanning Electron Microscopy, X-ray Diffraction, microhardness and tensile test. Several factors that affect uniform distribution of reinforcing particles were investigated. At the initial stages of ARB process particle free zones as well as particle clusters were observed in the microstructure of the composite. After 12 ARB cycles, a nanocomposite with a uniform distribution of nanoparticles was produced. It was shown that the tensile strength of the ARBed composite enhanced with the increasing number of ARB cycles. After the first cycle, a significant increase was observed in the tensile strength of nanocomposite in 2.0 percent volume of $\mathrm{WO}_{3 \mathrm{p}}$, from $89 \mathrm{MPa}$ to $128 \mathrm{MPa}$ (almost 1.4 times increase in strength). After the final cycle, the tensile strength value increased to $205 \mathrm{MPa}$ (that is almost 2.3 times increase in strength) due to the strain hardening and grain refinement. The X-ray diffraction results showed that $\mathrm{Al} / \mathrm{WO}_{3 \mathrm{p}}$ nanocomposite with the average crystallite size of $41 \mathrm{~nm}$ was successfully attained after 12 cycles of the ARB process. Finally, observations revealed that the fracture mode in $\mathrm{Al} / \mathrm{WO}_{3 \mathrm{p}}$ nanocomposite was of type shearing ductile fracture with elongated shallow dimples.
\end{abstract}

\section{Keywords}

Accumulative Roll Bonding, Nanocomposite, Microstructure, Mechanical Properties 


\section{Introduction}

Accumulative roll bonding (ARB) is of the severe plastic deformation methods proposed by Tsuji et al. [1] to achieve ultra-high strain in metallic materials without changing the specimen dimensions. The process that creates UFG materials is called severe plastic deformation [2] [3] [4] [5] [6]. Bulk materials with nano-grains $(\mathrm{d}<100 \mathrm{~nm})$ and UFG materials with small grains $(100 \mathrm{~nm} \leq \mathrm{d}<1$ $\mu \mathrm{m})$ due to their outstanding mechanical properties have been the focus of a considerable amount of research for potential use in structural materials in the industry. Ultra-fine grained materials have found a wide range of usage in different fields such as automotive, aerospace and engineering applications [2] [3]. There are several methods used to produce UFG materials [3]-[9]. Accumulative roll bonding is a conventional method to process UFG materials. The roll bonding technique has been extensively used to fabricate nanocomposites because of its low cost and efficiency. This method has two important strengthening mechanisms, one is formation of Nano/UFG structure by SPD and the other is reinforcing metal matrix by ceramic particles [10] [11]. Metal matrix composite materials are a group of particles reinforced by ceramic particles, layers or whiskers that have unique physical and mechanical properties [11] [12] [13]. More recently, ARB has been utilized to fabricate particulate metal matrix composites such as: $\mathrm{Al} / \mathrm{SiC}$ [14] [15] [16], $\mathrm{Al} / \mathrm{Al}_{2} \mathrm{O}_{3}$ [13] [17], $\mathrm{Al} / \mathrm{B}_{4} \mathrm{C}$ [18], $\mathrm{Al} / \mathrm{CNT}$ [19], $\mathrm{Al} / \mathrm{TiO}_{2}$ [20], $\mathrm{Al} / \mathrm{SiO}_{2}$ [21], $\mathrm{Al} / \mathrm{W}$ [22] [23], $\mathrm{Al} / \mathrm{WC}$ [24]. It has been shown that a uniform distribution of particles can be achieved after imposing a critical reduction to the sample where "reduction" is defined as decrease of about $50 \%$ or more of the mean thickness value of initial samples per roll cycle [12]. Addition of ceramic reinforcements (i.e. carbides and oxides) to the metal matrix composites enhances the properties such as elastic modulus, strength, wear, corrosion resistance, hardness and high-temperature durability [11]. In this research, tungsten trioxide $\left(\mathrm{WO}_{3}\right)$ nanoparticles with the density of $7.16 \mathrm{~g} / \mathrm{cm}^{3}$ were used as the reinforcement material. Also, with increase use of various radiations such as X-ray in industry, medicine, agriculture and defense, it has now become necessary to study new materials with good effective radiation shielding properties. The new materials could be used in the manufacturing of conducting and semi-conducting materials to be used in optics and mechanochemical applications with low density and high mechanical properties. Research of radiation shielding materials, which have significant application in national defense and civilian use, has been one of the most important subjects in the developed countries [25] [26] [27]. One of the important advantages of $\mathrm{WO}_{3}$ compared to pure tungsten and tungsten carbide is its low density. In this study the $\mathrm{Al} / \mathrm{WO}_{3 \mathrm{p}}$ nanocomposites were produced by ARB process where $\mathrm{WO}_{3}$ reinforced nanoparticles were dispersed directly during the initial cycles (see Section 2. experimental process). Accumulative roll bonding process was carried out up to 12 cycles. To the best of author's knowledge, in addition to the structural evolution and mechanical properties of $\mathrm{Al} / \mathrm{WO}_{3 \mathrm{p}}$ nanocomposites, investigation of different cycles of $\mathrm{ARB}$ on using $\mathrm{Al} / \mathrm{WO}_{3 \mathrm{p}}$ nanocomposites has been carried out for 
the first time. Several factors that are effective in uniform distribution of reinforcing particles were investigated.

\section{Experimental Process}

Commercial aluminum alloy sheets (AA1100) see Table 1 was used in this study. Cold rolled aluminum sheets with $120 \mathrm{~mm}$ length, $50 \mathrm{~mm}$ width, and $1 \mathrm{~mm}$ thickness were sandwiched together with reinforcing particles before passing through the rollers (See Figure 1). The aluminum sheets were annealed for 60 min at $400^{\circ} \mathrm{C}$, to ensure consistent specimen hardness [28] [29] [30].

Tungsten trioxide nanoparticles $\mathrm{WO}_{3 \mathrm{p}}$ with $80 \mathrm{~nm}$ average diameter of $99.9 \%$ purity with 1.0, 1.5 and 2.0 percent by volume were used as the reinforcement. Figure 2 shows the image of Field Emission-Scanning Electron Microscopy (FE-SEM) and X-ray Diffraction (XRD) patterns analysis of the $\mathrm{WO}_{3}$ nanoparticles for the current study. The preparation processes for the specimens included degreasing with acetone bath followed by scratch-brushing with a stainless steel brush. To avoid any oxidation or interference with bonding, the roll bonding process must be carried out immediately after degreasing and scratch brushing [13] [20]. The roll bonding process was carried out with no lubrication, using a laboratory rolling mill with a loading capacity of 20 tons. The roll diameters were $120 \mathrm{~mm}$, and the rolling speed was $35 \mathrm{RPM}$. Then the tensile test

Table 1. Specifications of the commercial purity of aluminum alloy (AA1100).

\begin{tabular}{ccccc}
\hline Material & $\begin{array}{c}\text { Chemical Composition } \\
(\% \text { by weight })\end{array}$ & $\begin{array}{c}\text { Tensile Strength } \\
(\mathrm{MPa})\end{array}$ & $\begin{array}{c}\text { Elongation } \\
(\%)\end{array}$ & $\begin{array}{c}\text { Micro-Hardness } \\
(\mathrm{HV})\end{array}$ \\
\hline $\begin{array}{c}\text { AA1 } 100 \\
\text { annealed }\end{array}$ & $\begin{array}{c}0.18 \mathrm{Si}, 0.37 \mathrm{Fe}, 0.13 \mathrm{Cu}, 0.02 \mathrm{Mn}, \\
99.28 \mathrm{Al}, 0.02 \text { others }\end{array}$ & 89 & 45 & 38 \\
\hline
\end{tabular}

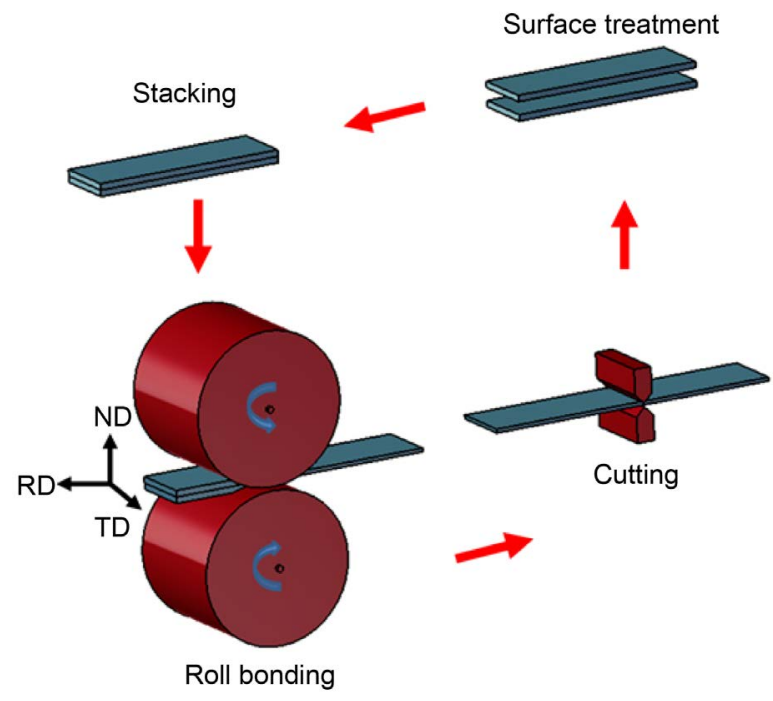

Figure 1. Schedule of accumulative roll bonding used in the present work. The reference axes are defined as rolling direction (RD), transverse direction (TD) and normal direction (ND). 


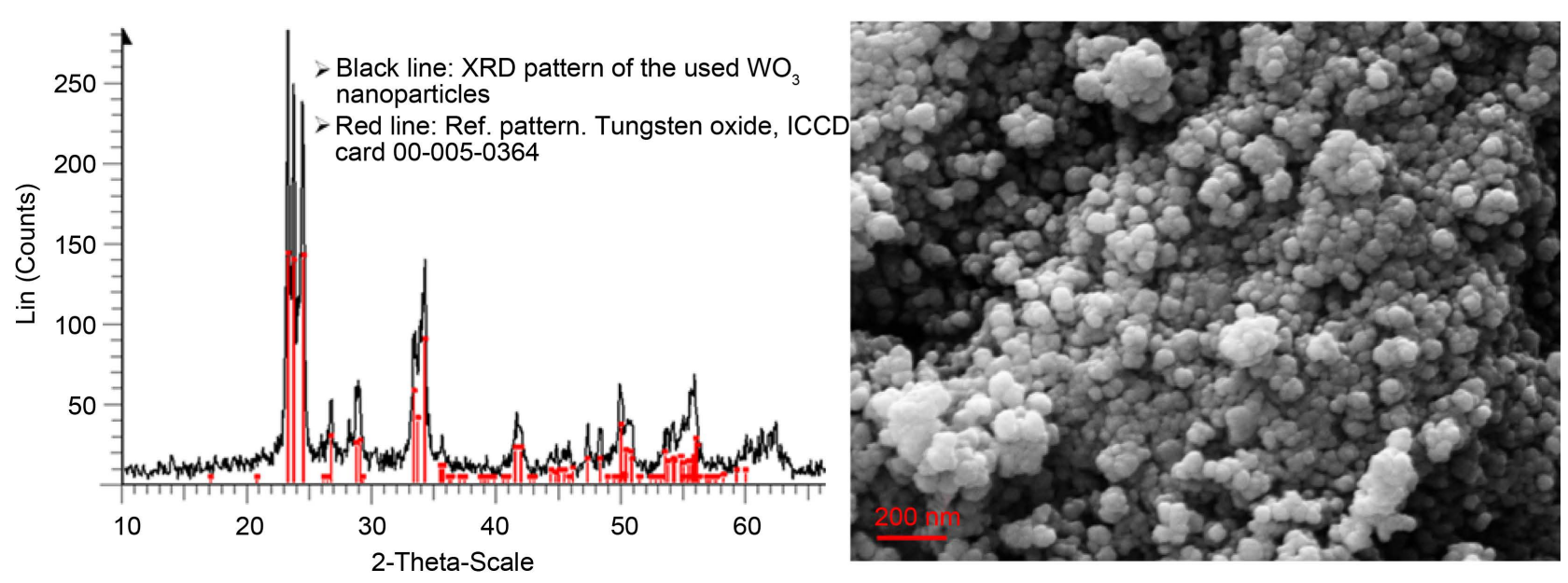

Figure 2. Typical FE-SEM image and $\mathrm{XRD}$ analysis of the used $\mathrm{WO}_{3}$ powder.

samples were machined from the ARBed sheets, according to the ASTM E8M standard, oriented along the rolling direction. The gauge width and length of the tensile test samples were 6 and $25 \mathrm{~mm}$, respectively. Tensile test at ambient temperature was carried out at a nominal strain rate of $8.3 \times 10^{-4} \mathrm{~s}^{-1}$ by using DarTec universal testing machine. The total elongation of the specimens was determined as the difference between gauge lengths before and after testing.

Vickers micro hardness (HV) measurement was done by Bohler MMT-7 under a load of $50 \mathrm{~g}$ and time of $25 \mathrm{~s}$ on nanocomposites rolling direction \& transverse direction (RD-TD) planes. Microhardness test was performed on all samples in more than ten randomly selected points and the average number was reported. The X-ray pattern of the produced $\mathrm{Al} / \mathrm{WO}_{3 \mathrm{p}}$ nanocomposite was achieved by X-ray diffractometer (XRD) to characterize the structure. The crystallite size of the specimen (i.e., mean diameter, d) was calculated from the XRD patterns applying the Williamson-Hall method (Equation (1)) [22] [31].

$$
d=k \lambda / \beta \cos \theta-2 A \varepsilon \sin \theta
$$

In the above equation $\mathrm{d}$ is the crystallite size, is the Bragg diffraction angle, is the average internal strain, is the wavelength of X-ray $(0.154056 \mathrm{~nm}$ for $\mathrm{Cu} \mathrm{Ka}$ radiation), is the diffraction peak width at half maximum intensity, $k$ is the Sherrer constant (0.91), and A is a coefficient depending on the distribution of strain, which is near unity for dislocations. By extrapolating the interception of vs., the average size of crystals is obtained.

\section{Results and Discussion}

\subsection{Microstructural Investigations}

In Figure 3, FE-SEM shows the microstructure of 1.5 percent by volume reinforcing particles of nanocomposite by the ARB process. Figure 3(a) shows the fifth cycle of produced nanocomposite by ARB process, which leads to fragmentation and separation of $\mathrm{WO}_{3 \mathrm{p}}$ clusters in $\mathrm{Al}$ matrix. Many factors influence the creation of strain hardening and grain refinement in $\mathrm{Al} / \mathrm{WO}_{3 \mathrm{p}}$ nanocomposites are as follows: 

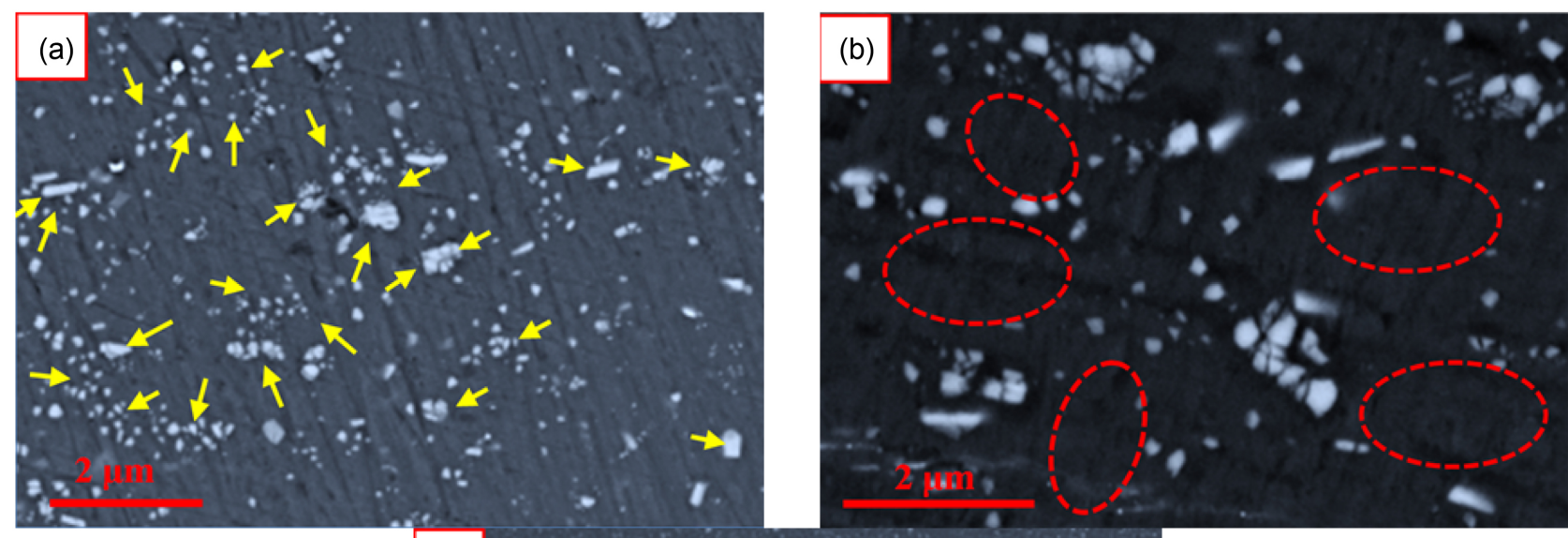

(c)

Figure 3. FE-SEM images of microstructure nanocomposite produced during ARB process: (a) some zones of agglomerated reinforcing particles; (b) zones free of reinforcing particles and particle clusters; (c) the microstructure of nanocomposites reinforced with $\mathrm{WO}_{3 \mathrm{p}}$ at final cycle.

1) Samples preparation-wire-brushing which causes abundant residual stress in the samples [32] [33].

2) Shear strain-during the process of $A R B$, shearing strain occurs as a result of friction between the rollers and the surface of the sample without lubricant as reported by Lee et al. [33]. This factor has a special role in strain hardening and grain refinement.

3) Particle reinforcement-influences strain hardening through: a) barriers to dislocation motion, b) difference in matrix coefficient of thermal expansion, and reinforcing particles. Which creates stress in the spaces between the reinforcing particles and the matrix, and c) increasing the number of dislocation motions as reported by Orowan mechanism [34] [35].

The X-ray diffraction results also showed that nanocomposite of $\mathrm{Al} / \mathrm{WO}_{3 \mathrm{p}}$ microstructure with the average crystallite size of 1.0, 1.5 and 2.0 percent by volume of reinforcing particles was $95.2,70.7$ and $41.2 \mathrm{~nm}$, respectively that successfully achieved by employing twelve cycles of ARB process. Figure 3(a) shows cluster zones of $\mathrm{WO}_{3}$ reinforcing particles in the matrix. With increase in the production of composite cycle by the ARB process, reinforcing particles constantly get out of cluster mode during each cycle and dispersed throughout the sample to achieve uniform distribution in the matrix [19]. Figure 3(b) shows 
$\mathrm{Al} / \mathrm{WO}_{3 \mathrm{p}}$ composite matrix produced by the $\mathrm{ARB}$ process including clusters and free zones of reinforcing particles. With each cycle in the process of ARB, the fragmented zones (see Figure 3(b)) dispersed and moved into the matrix providing more uniform distribution within the matrix. Figure $3(\mathrm{c})$ shows $\mathrm{Al} / \mathrm{WO}_{3 \mathrm{p}}$ nanocomposite at the microstructure level with an appropriate distribution of reinforcing particles into the matrix in the final cycle (twelfth cycle). Several factors are effective in uniform distribution of reinforcing particles. To name a few one can mention: 1) The influence of the applied strain, reduction and the shear bonds-With increasing the rate of strain (i.e., increasing number of cycles) a more uniform distribution of reinforcing particles is achieved. Since in the ARB process the strain along the thickness of the samples without the use of lubricant is at least $80 \%$ (for $50 \%$ reduction) therefore, high friction is created between the specimen sheets and the rollers [19] [30]. By increasing reduction, the amount of strain hardening in the samples increases too. According to reference [33], on the structure rolled sheet by ARB process, it can be seen that the increase of strain, grain size reduces and grain refinement takes place. By applying the same strain, localized shear bands are formed in the sample causing a greater tendency towards plastic deformation resulting in the improvement in grain refinement. Min et al. [36] reported that shear bands are formed around the intersection of matrix and reinforcing particles. Shear bands move within the matrix and cause the clusters (reinforcing particles) to be broken and fragmented, leading to displacement of reinforcing particles and their distribution. 2) Crystal structure and stacking-fault energy (SFE)-have been the focus of a lot of researchers where they used metals with different crystal structures to produce composites by the ARB process [37] [38]. Metals have different sliding plates according to their crystalline structures. For example, FCC crystal structures have 12 sliding systems $\langle 110\rangle$ (111) resulting in a more formability than metals with HCP and BCC crystal structures. According to reports [36] [37] [38], Al and $\mathrm{Cu}$ have more formability than $\mathrm{Ti}$ and $\mathrm{Zn}$ in where then FCC and $\mathrm{HCP}$ crystalline structure, respectively. Thus, the rate of uniform distribution of reinforcing particles in metals with FCC crystal structure is much faster than metals with HCP crystal structure. This is due to more formability of metals with FCC crystal structures. On the other hand, metals with similar crystalline structures have different SFE, which is an inherent property of the metals. SFE plays an important role in determining the strength and ductility of FCC metals. The stacking-fault energy is related to the atomic bonding in materials. It determines the extent of unit dislocations dissociated into partial dislocations. In practice, the width of the stacking fault ribbon, between the two Shockley partial in crystalline solids, is a significant feature, which controls the rate of dislocation in cross slip and climb. In fact, metals with highs and lows of SFE are found by the system slip and twin slip deformation respectively. Stacking Fault Energy for aluminum is $166 \mathrm{~mJ} / \mathrm{m}^{2}$ while for copper and brass is $78 \mathrm{~mJ} / \mathrm{m}^{2}$ and $20 \mathrm{~mJ} / \mathrm{m}^{2}$ respectively [38]. Thus, by increasing the SFE, formability becomes much easier and hence the rate of reinforcing particle distribution increases. 3) Tempera- 
ture-Temperature is advantageous for join-ability and workability, though very high temperatures would cause recrystallization and eliminates the accumulated strain effects. The temperature of the process and the accumulated strain determines the amount of recrystallization [39]. At higher dislocation, movement becomes easier and their changes are relative to stacking fault energy of each material. According to [40] "the continuous changes in misorientation are converted into the high angle boundaries $(\theta>15$ degrees) by rearrangement of the geometry necessary dislocations through short range diffusion. The short range diffusion is possible even at ambient temperature due to the temperature increase caused by plastic deformation even if it was conducted at room temperature". The nanoparticles can be considered as the obstacles to the dislocation motions and also the dislocations accumulation. High dislocations density causes the higher rate of diffusion. Hence, the sub-grain boundaries (formed by rearrangements of the dislocations) further evolve into grain boundaries with a large angle of misorientation, and therefore, grain refinement facilitates [41]. As temperature increases, more sliding systems is activated and the phenomena of cross slip and dislocation climb occurs more frequently. These factors mentioned above, can lead to separation, movement and distribution of reinforcing particles, of clustered within the matrix [32]. 4) Reinforcing particles size and grain boundary-R. Jamaati et al. [17] studied the effect of reinforcing particles size based on micro scale and their distribution in the matrix by the ARB process. It was reported that composite with larger reinforcing particles achieve a more uniform distribution comparing to composite with small reinforcing particles. However, at the end of the cycle, the composite with small reinforcing particles show a higher strength with respect to composite with larger reinforcing particles. Reinforcing nanoparticles seems to play a role similar to smaller reinforcing particles. The nanocomposite produced by reinforcing nanoparticles has higher strength compared to those produced by reinforcing macro particles. Since there are more obstacles in nanocomposites or smaller reinforcing particles to impede the dislocation movement, it causes locking mechanism and also dislocation accumulation in the spaces between the reinforcing particles and the matrix. Accordingly, it can be said that this result is the structural evolution where nanocomposite achieves nanostructure faster. On the other hand, reinforcing particles are mostly around grain boundaries or in the zones of highenergy. However, during the ARB process along with structure refinement and production of UFG materials, the grain boundaries are increased, resulting in a more appropriate distribution of reinforcing nanoparticles in the matrix for the produced composite.

\subsection{Mechanical Properties}

\subsubsection{Tensile Strength and Elongation}

Figure 4(a) and Figure 4(b) show tensile strength and elongation-numbers within selected cycles for the $\mathrm{Al} / \mathrm{WO}_{3 \mathrm{p}}$ nanocomposite. In these two figures (Figure 4(a) and Figure 4(b)), tensile strength and elongation are highly influ- 


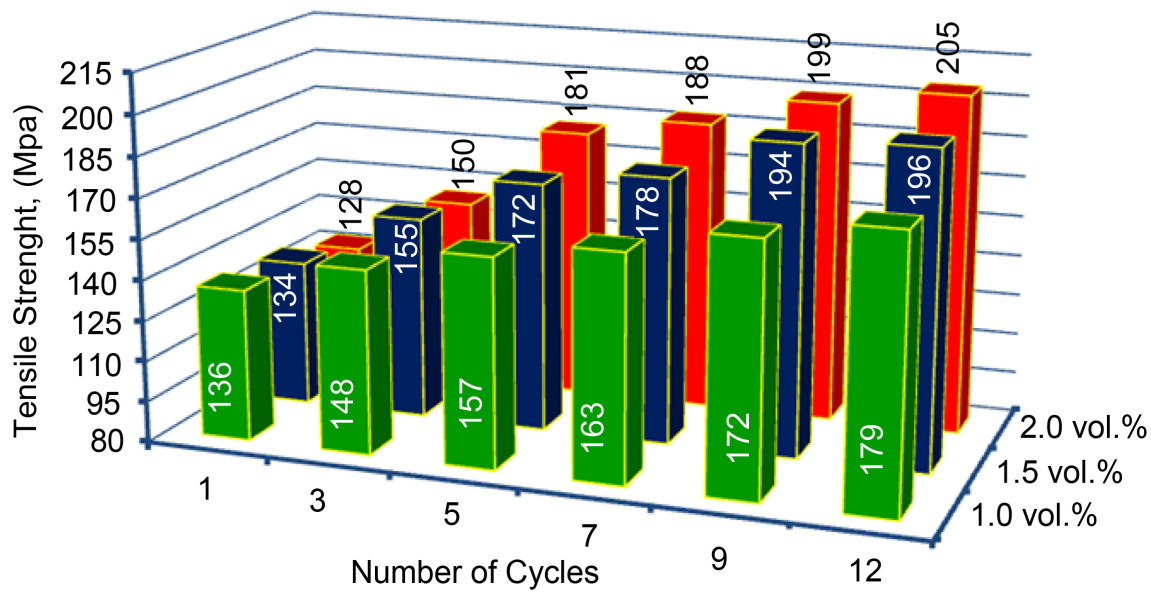

(a)

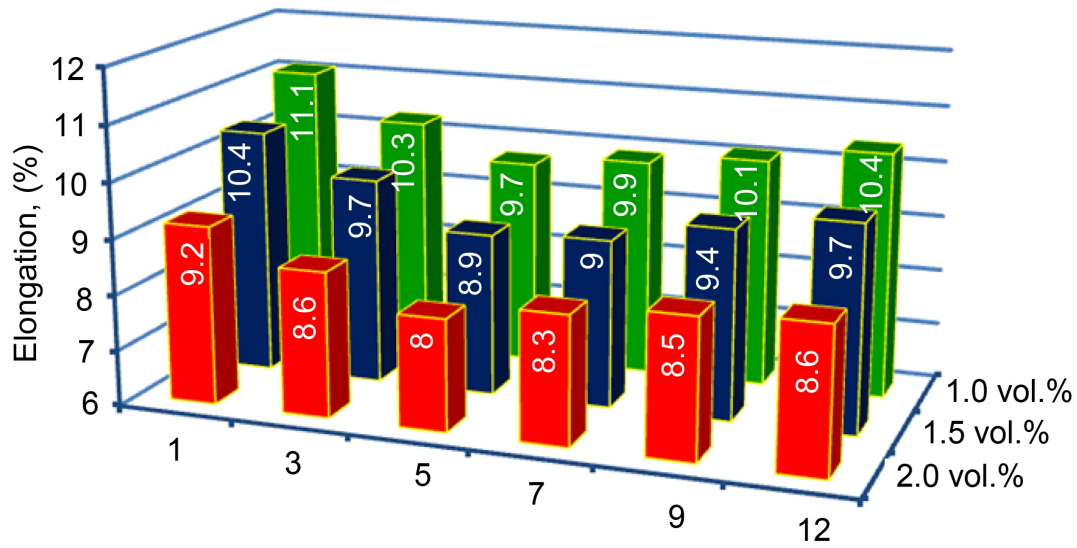

Number of Cycles

(b)

Figure 4. (a) and (b) show images of tensile strength and elongation-number of cycles for $\mathrm{Al} / \mathrm{WO}_{3 \mathrm{p}}$ nanocomposite produced by the $\mathrm{ARB}$ process.

enced by the number of cycles (i.e., the strain). While processing ARB, strain hardening and grain refinement influence strengthening and elongation. It can be stated that in the early cycles of ARB process, strain hardening plays an essential role in increasing the strength. However, by increasing number of cycles (or increasing strain), strain hardening is replaced with grain refinement, which is more dominant [19]. In Figure 4(a) the tensile strength of the $\mathrm{Al} / \mathrm{WO}_{3 \mathrm{p}}$ nanocomposites increases as percent volume of reinforcing particles increases within the cycles. Composite strength at the beginning of the cycles is increased with steeper slope compared with the raw annealed sheets of aluminum due to strain hardening \& anisotropic phenomena. This is because of the higher reduction rolling effect (about 50\%). There is a relationship between the increase of strain and strength but the rate of increase lowers as strain increase. This is known as saturation of strain hardening [30] [33]. In high strains (i.e. finishing cycle) two factors of strain hardening and grain refinement interfere with each other. It must be noted that grain refinement plays a more important role than strain hardening [30] [32]. Rate of strain hardening in each of the introduced particles 
is different from each other and it's based on the matrix. As the cycles increase, the clusters tend to reduce and the particles distant themselves from each other. This strain hardening to uniformly be distributed accuses the matrix, which in turn produces a uniform grain refinement in the sample. For $\mathrm{Al} / \mathrm{WO}_{3 \mathrm{p}}$ nanocomposite with 1.0, 1.5 and 2.0 percent by volume of reinforcing particles, tensile strengths of 181, 196 and $199 \mathrm{MPa}$ were achieved and by increasing $\mathrm{WO}_{3}$ reinforcing particles, tensile strength also increased. Proper distribution of $\mathrm{WO}_{3}$ reinforcing particles in aluminum matrix improves the strength of $\mathrm{Al} / \mathrm{WO}_{3 \mathrm{p}}$ nanocomposite produced. The uniform distribution of reinforcing particles (Figure 3(c)) has been achieved in cycle 12. According to R. Jamaati et al. [42] [43], two types of porosities are observed in the ARB samples and they are either caused by lack of proper bonding between the sheets and/or resulting from early non-adherence of reinforcing particles to the matrix. By increasing the number of cycles, the bonds between $\mathrm{WO}_{3}$ nanoparticles and aluminum matrix improves and increases the bond between the sheets, strength and consequently reduces the porosity.

Due to almost half in coefficient of thermal expansion of the reinforcing particles $\left(13 \times 10^{-6} / \mathrm{K}\right)$ compared with aluminum matrix $\left(23.86 \times 10^{-6} / \mathrm{K}\right)$ during the ARB process thermal stresses are created at the intersection between reinforcing nanoparticles and the matrix. This leads to increase in tensile strength and reduction of elongation [24]. Figure 4(b) shows that during the ARB process, the elongation of different volume percentage reduces rapidly at first and continues to about the fifth cycle then increases with moderate rate to cycle 12. Finally, elongations of 10.4, 9.7 and 8.6 were reached for 1.0, 1.5 and 2.0 percent by volume of reinforcing particles, respectively.

\subsubsection{Hardness}

Figure 5 shows microhardness corresponding to cycles of ARBed samples with respect to monolithic and nanocomposite in different volume percentages of reinforcing nanoparticles of $\mathrm{WO}_{3}$. Some factors that influence the hardness of ARBed samples as discussed by [39] are: brushing the samples before rolling, strain hardening due to the surface friction between the roll and samples, grain refinement by dynamic recovery, reinforcing particles and reduced porosity in the samples. As it can be seen in the Figure 5, three zones are produced during ARB process. Rapid increase of microhardness in zone (1) within the initial cycles is due to strain hardening (based on dislocation density and dislocation effects on each other). Creation of forest dislocations caused by strain hardening and locking them together increases both strength and microhardness. It should be noted that, hardness saturation of UFG materials by SPD for the first time has been reported in reference [38] [39].

Hardness in $\mathrm{Al} / \mathrm{WO}_{3 \mathrm{p}}$ nanocomposite samples is greater than that of $\mathrm{ARBed}$ monolithic samples. This is due to obstacles hindering motions of reinforcing nanoparticles and locking them together. It can be stated that in zone (1) the role of strain hardening is more important than the role of dynamic recovery for 


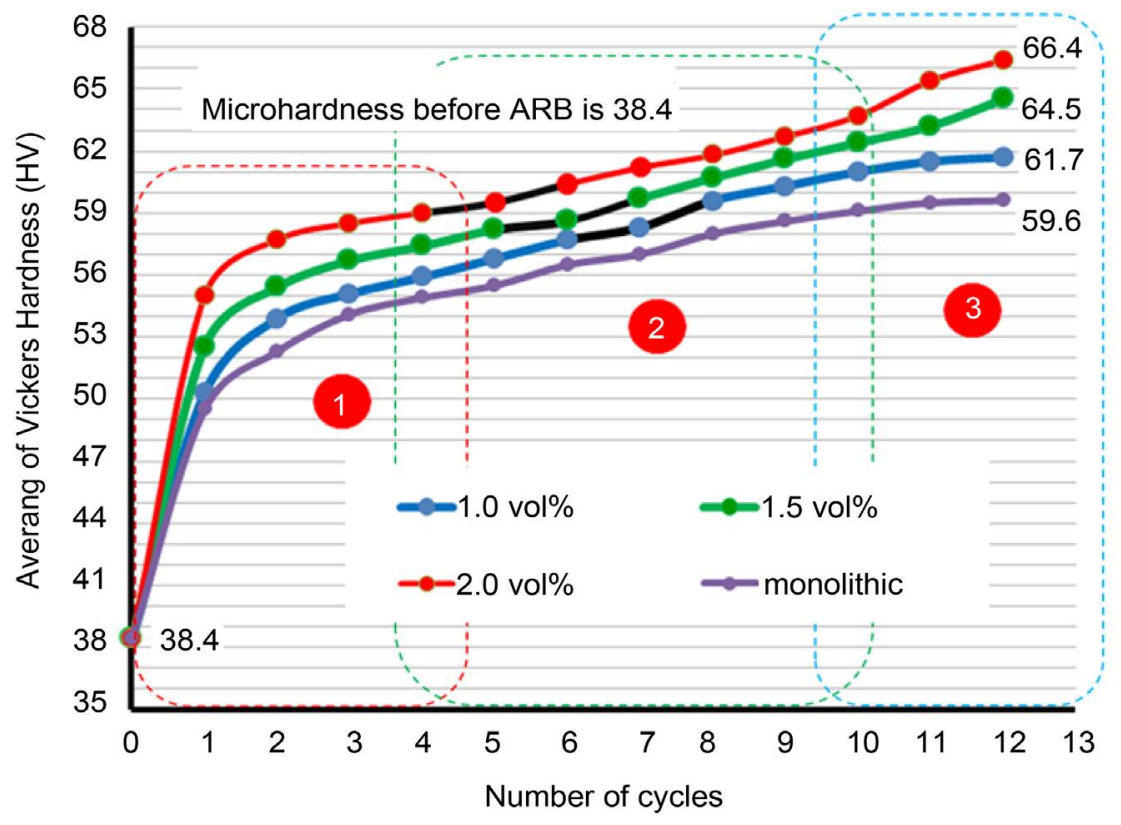

Figure 5. Shows the changes of microhardness of monolithic and produced nanocomposite for 1.0, 1.5 and 2.0 percent of volume $\mathrm{WO}_{3}$ reinforced nanoparticles.

increasing hardness. In zone (2) the rate of increase in hardness is more moderate due to competition between strain hardening and dynamic recovery [32] [38]. In this zone the impact of dynamic recovery is increased compared with zone (1) and the rate of increase in hardness slows down with increasing number of cycles (increasing strain) in zone (2) [38] [42]. Increasing the number of cycles creates a more uniform distribution of reinforcing nanoparticles and reduces the amount of porosity, which in turn increases hardness. In zone (3) of Figure 5 no significant increase in hardness is seen. The effect of reinforcing nanoparticles is very important as it is evident in zone (3) where the amount of hardness in nanocomposite samples is more than ARBed monolithic samples. A decrease in the microhardness of samples in specific cycles (Black lines) of ARB process is visible which may be due to dislocation in annihilating process. This leads to work softening and decrease of hardness in the matrix. For more cycles, with increase of dislocation density and grain refinement, microhardness of materials rises and reaches to maximum value in twelfth cycle of ARB process [43]. As it can be seen in Figure 5, composite samples of microhardness after 12 cycles for 1.0, 1.5 and 2.0 percent by volume of reinforcing particles increased to about 62, 64.5 and $67 \mathrm{HV}$ respectively compared to ARBed of pure samples. In addition, the hardness was raised due to dislocations formed in the grains, an important effect which could also affect the final hardness. Table 2 shows the mechanical properties of produced nanocomposites compare to some composites produced by ARB process.

\subsection{Fracture Surface}

Figure 6 shows $\mathrm{FE}-\mathrm{SEM}$ images of $\mathrm{Al} / \mathrm{WO}_{3 \mathrm{p}}$ nanocomposite fracture surface in 
Table 2. Comparison of mechanical properties of produced nanocomposites, monolithic and other produced composites by tungsten reinforcing particles.

\begin{tabular}{ccccc}
\hline Material & $\begin{array}{c}\text { Tensile Strength } \\
(\mathrm{MPa})\end{array}$ & $\begin{array}{c}\text { Hardness } \\
(\mathrm{HV})\end{array}$ & $\begin{array}{c}\text { Crystallite Size } \\
(\mathrm{nm})\end{array}$ & Reference \\
\hline AA1100 ARBed & 160 & 59.6 & 365.2 & This work \\
Composite 1.0 vol.\% $\mathrm{WO}_{3 \mathrm{p}}$ & 179 & 61.7 & 95.2 & This work \\
Composite 1.5 vol.\% $\mathrm{WO}_{3 \mathrm{p}}$ & 196 & 64.5 & 70.7 & This work \\
Composite 2.0 vol.\% $\mathrm{WO}_{3 \mathrm{p}}$ & 205 & 66.4 & 41.2 & This work \\
Composite $\mathrm{WC}$ & 175 & 61 & - & {$[23]$} \\
Composite 4.2 vol.\% W & 160 & 59.98 & - & {$[24]$} \\
\hline
\end{tabular}
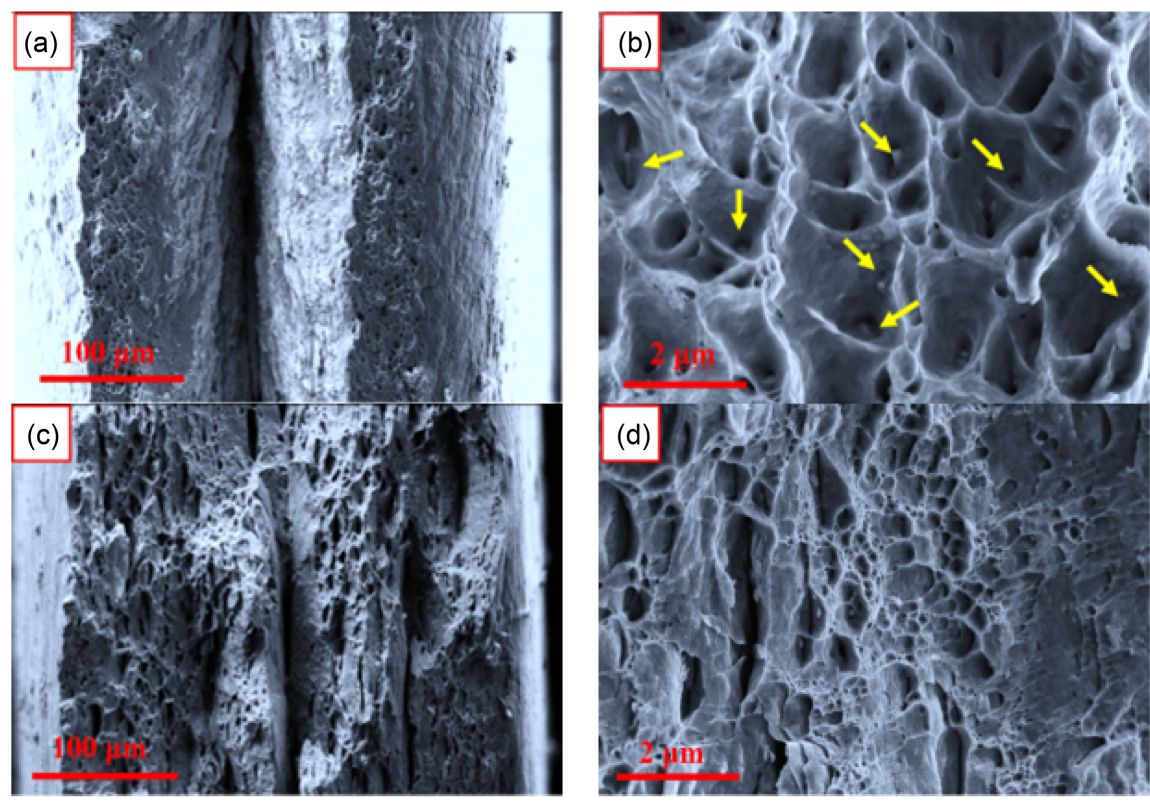

Figure 6. Fracture surfaces of produced nanocomposite in the first and final cycle in the (a) (b) and (c), (d) at different magnifications respectively.

the first cycle and final cycle (twelfth cycle) with different magnifications. In Figure 6(a) and Figure 6(b), ductile fractures with deep pores in coaxial directions are observed.

It can be seen than fracture has a gray appearance with almost similar spherical pores [25] [44]. Fracture was first caused by the formation of micro-pores and their connection to each other [26] [45]. Nanocomposite samples produced by the ARB process reinforcing nanoparticles play an effective role in creating micro-cracks. Cracks are first created in the intersection between the matrix and reinforcing particles [24] [26]. In Figure 6(b), $\mathrm{WO}_{3}$ reinforcing nanoparticles inside the pores can be seen. They cause localized stresses around themselves. Reinforcing particles increase shear deformation and reduce the growth of pores. There are two ductile fracture mechanisms. One is development of pores and their interconnection and the other is cutting pores and internal links (ductile shear). As shown in Figure 6(c) and Figure 6(d), by increasing number of cycle, fracture changed and the size, shape (i.e., stretched), and the quantity of pores 
became finer and stretched more as reported by [44] [46] [47].

\section{Conclusions}

New nanocomposite with $\mathrm{WO}_{3}$ nanoparticle distribution is manufactured through 12 cycles of ARB process. The structural characteristics of crystallite size, fracture surface and mechanical properties such as tensile strength, elongation and hardness of the produced nanocomposite were investigated. The conclusions can be summarized as follows:

$\mathrm{Al} / \mathrm{WO}_{3 \mathrm{p}}$ nanocomposite is successfully produced in the form of a sheet through ARB process. A uniform distribution of nanoparticles is observed in the microstructure for high ARB cycles ( $12^{\text {th }}$ cycles).

Several factors are effective in uniform distribution of reinforcing particles that include: influence of the applied strain, reduction, shear bands, crystal structure, stacking fault energy, temperature, reinforcing particles size and grain boundary.

The X-ray diffraction results showed that structure of $\mathrm{Al} / \mathrm{WO}_{3 \mathrm{p}}$ nanocomposite with the average crystallite size of 1.0, 1.5 and 2.0 percent by volume of reinforcing particles were 95.2, 70.7 and $41.2 \mathrm{~nm}$ respectively and was successfully achieved by employing 12 cycles of ARB process.

The tensile strength and elongation of the nanocomposite rises with increasing the number of ARB cycles. It can be concluded that additional strengthening mechanisms have contributed to the presence of the nanoparticles in the nanocomposite. After $12^{\text {th }}$ cycles the tensile strength and elongation of the nanocomposite (with 2.0 percent by volume of reinforcing particles) reaches $205 \mathrm{MPa}$ and 8.6 , respectively.

The hardness increases by increasing the $\mathrm{WO}_{3}$ reinforcing nanoparticle in the $\mathrm{Al}$ matrix. The hardness of nanocomposite with 2.0 percent by volume of reinforcing particles was about $67 \mathrm{HV}$.

Studying the fracture surface in images of FE-SEM, revealed large and deep dimples are at the fracture surface of the nanocomposite, indicating that nanoparticles have a significant effect on the ductility of the nanocomposite.

\section{Acknowledgements}

This work was financially supported by Semnan University and Oghab Afshan Industrial \& Manufacturing Company. The authors are grateful for these supports. Also, J.K. Khabushan thanks Dr. A. Honarbakhsh-Raouf for informative discussion and Dr. H. Memar for edit of this investigation.

\section{References}

[1] Tsuji, N., Saito, Y., Lee, S. and Minamino, Y. (2003) Accumulative Roll Bonding and Other New Techniques to Produce Bulk Ultrafine Grained Materials. Advanced Engineering Materials, 5, 338-344. https://doi.org/10.1002/adem.200310077

[2] Valiev, R.Z. and Langdon, T.G. (2006) Principles of Equal Channel Angular Pressing as a Processing Tool for Grain Refinement. Progress in Materials Science, 51, 
881-981.

[3] Anghelus, A., Avettand-Fènoël, M.N., Cordier, C. and Taillard, R. (2015) Microstructural Evolution of Aluminium/Al-Ni-Sm Glass Forming Alloy Laminates Obtained by Controlled Accumulative Roll Bonding. Journal of Alloys and Compounds, 631, 209-218.

[4] Valiev, R.Z., Islamgaliev, R.K. and Alexandrov, I.V. (2000) Bulk Nanostructured Materials from Severe Plastic Deformation. Progress in Materials Science, 45, 103 189.

[5] YousefiMehr, V., Rezaeian, A. and Toroghinejad, M.R. (2015) Application of Accumulative Roll Bonding and Anodizing Process to Produce $\mathrm{Al}-\mathrm{Cu}-\mathrm{Al}_{2} \mathrm{O}_{3}$ Composite. Materials and Design, 70, 53-59.

[6] Gazder, A.A., Hazra, S.S. and Pereloma, E.V. (2011) Annealing Behaviour and Mechanical Properties of Severely Deformed Interstitial Free Steel. Materials Science and Engineering: $A$, 530, 492-503.

[7] Liu, X., Wei, D., Zhuang, L., Cai, C. and Zhao, Y. (2015) Fabrication of High Strength Graphene Nanosheets/Cu Composites by Accumulative Roll Bonding. Materials Science and Engineering. A, 642, 1-6.

[8] Gashti, S.O., Fattahalhosseini, A., Mazaheri, Y. and Keshavarz, M.K. (2016) Effect of Grain Refinement on Mechanical and Electrochemical Properties of Ultra Fine Grained AA1050 Fabricated via ARB Process. Journal of Manufacturing Processes, 22, 269-277.

[9] Richert, J. and Richert, M. (1986) A New Method for Unlimited Deformation of Metals and Alloys. Aluminium, 62, 604.

[10] Eizadjou, M., Talachi, A.K., Manesh, H.D., Shahabi, H.S. and Janghorban, K. (2008) Investigation of Structure and Mechanical Properties of Multi Layered $\mathrm{Al} / \mathrm{Cu}$ Composite Produced by Accumulative Roll Bonding (ARB) Process. Composites Science and Technology, 68, 2003-2009.

[11] Hosseini, S.M., Habibolahzadeh, A., Petráňová, V. and Němeček, J. (2016) Influence of Nano-SiCp on the Foamability and Microstructure of $\mathrm{Al} / \mathrm{TiH}_{2}$ Foam Sheet Manufactured by Continual Annealing and Roll Bonding Process. Materials and Design, 97, 483-491.

[12] Reihanian, M., Bagherpour, E. and Paydar, M.H. (2013) On the Achievement of Uniform Particle Distribution in Metal Matrix Composites Fabricated by Accumulative Roll Bonding. Materials Letters, 91, 59-62.

[13] Jamaati, R., Toroghinejad, M.R., Dutkiewicz, J. and Szpunar, J.A. (2012) Investigation of Nanostructured $\mathrm{Al} / \mathrm{Al}_{2} \mathrm{O}_{3}$ clComposite Produced by Accumulative Roll Bonding Process. Materials and Design, 35, 37-42.

[14] Amirkhanlou, S., Jamaati, R. and Niroumand, B. (2011) Fabrication and Characterization of $\mathrm{Al} / \mathrm{SiC}_{\mathrm{p}}$ Composites by CAR Process. Materials Science and Engineering: $A$, 528, 4462-4467.

[15] Jamaati, R., Amirkhanlou, S., Toroghinejad, M.R. and Niroumand, B. (2011) Effect of Particle Size on Microstructure and Mechanical Properties of Composites Produced by ARB Process. Materials Science and Engineering. A, 528, 2143-2148.

[16] Alizadeh, M. and Paydar, M.H. (2010) Fabrication of Nanostructure Al/SiC $\mathrm{P}_{\mathrm{P}} \mathrm{Com}$ posite by Accumulative Roll-Bonding (ARB) Process. Journal of Alloys and Compounds, 492, 231-235.

[17] Jamaati, R. and Toroghinejad, M.R. (2010) High Strength and Highly Uniform Composite Produced by Anodizing and Accumulative Roll Bonding Processes. Materials and Design, 31, 4816-4822. 
[18] Yazdani, A. and Salahinejad, E. (2011) Evolution of Reinforcement Distribution in Al- $\mathrm{B}_{4} \mathrm{C}$ Composites during Accumulative Roll Bonding. Materials and Design, 32, 3137-3142.

[19] Karimi, M., Toroghinejad, M.R. and Dutkiewicz, J. (2016) Nanostructure Formation during Accumulative Roll Bonding of Commercial Purity Titanium. Materials Characterization, 122, 98-103.

[20] Soltani, M.A., Jamaati, R. and Toroghinejad, M.R. (2012) The Influence of $\mathrm{TiO}_{2}$ Nano Particles on Bond Strength of Cold Roll Bonded Aluminum Strips. Materials Science and Engineering. A, 550, 367-374.

[21] Hashemi, M., Jamaati, R. and Toroghinejad, M.R. (2012) Microstructure and Mechanical Properties of $\mathrm{Al} / \mathrm{SiO}_{2}$ Composite Produced by CAR Process. Materials Science and Engineering: A, 532, 275-281.

[22] Amirkhanlou, S., Ketabchia, M., Parvin, N., Khorsand, Sh. and Bahrami, R. (2013) Accumulative Press Bonding; a Novel Manufacturing Process of Nanostructured Metal Matrix Composites. Materials and Design, 51, 367-374.

[23] Liu, C.Y., Wang, Q., Jia, Y.Z., Zhang, B., Jing, R., Ma, M.Z., et al. (2013) Evaluation of Mechanical Properties of 1060-Al Reinforced with WC Particles via Warm Accumulative Roll Bonding Process. Materials and Design, 43, 367-372.

[24] Liu, C.Y., Wang, Q., Jia, Y.Z., Zhang, B., Jing, R., Ma, M.Z., Jing, Q. and Liu, R.P. (2012) Effect of W Particles on the Properties of Accumulatively Roll Bonded Al/W Composites. Materials Science and Engineering: A, 547, 120-124.

[25] Prasad, S.G., Parthasaradhi, K., Bloomer, W.D., et al. (1998) Aluminum, Copper, Tin and Lead as Shielding Materials in the Treatment of Cancer with High Energy Electrons. Radiation Physics and Chemistry, 53, 361-366.

[26] Singh, N., Singh, K.J., Singh, K., et al. (2004) Comparative Study of Lead Borate and Bismuth Lead Borate Glass Systems as Gammaradiation Shielding Materials. Nuclear Instruments and Methods in Physics Research Section B, 225, 305-309.

[27] Cucinotta, F.A., Myung-Hee, Y.K. and Ren, L. (2006) Evaluating Shielding Effectiveness for Reducing Space Radiation Cancer Risks. Radiation Measurements, 41, 1173-1185.

[28] Takata, N., Okitsu, Y. and Tsuji, N. (2008) Dynamic Deformation Behavior of Ultrafine Grained Aluminum Produced by ARB and Subsequent Annealing. Journal of Materials Science, 43, 7385-7390. https://doi.org/10.1007/s10853-008-2972-8

[29] Tsuji, N., Toyoda, T., Minamino, Y., Koizumi, Y., Yamane, T., et al. (2003) Microstructural Change of Ultrafine Grained Aluminum during High Speed Plastic Deformation. Materials Science and Engineering. A, 350, 108-116.

[30] Kamikawa, N., Tsuji, N., Huang, X. and Hansen, N. (2006) Quantification of Annealed Microstructures in ARB Processed Aluminum. Acta Materialia, 54, 30553066.

[31] Williamson, G.K. and Hall, W.H. (1953) X-ray Line Broadening from Filed Aluminium and Wolfram. Acta Metallurgica, 1, 22-31.

[32] Fattahalhosseini, A., Naseri, M. and Alemi, M.H. (2016) Corrosion Behavior Assessment of finely Dispersed and Highly Uniform $\mathrm{Al} / \mathrm{B}_{4} \mathrm{C} / \mathrm{SiC}$ Hybrid Composite Fabricated via Accumulative Roll Bonding Process. Journal of Manufacturing Processes, 22, 120-126.

[33] Lee, S.H., Saito, Y., Tsuji, N., Utsunomiya, H. and Sakai, T. (2002) Role of Shear Strain in Ultragrain Refinement by Accumulative Roll Bonding (ARB) Process. Scripta Materialia, 46, 281-285.

[34] Baazamat, S., Tajally, M. and Borhani, E. (2015) Fabrication and Characteristic of 
Al-Based Hybrid Nanocomposite Reinforced with $\mathrm{WO}_{3}$ and $\mathrm{SiC}$ by Accumulative Roll Bonding Process. Journal of Alloys and Compounds, 653, 39-46.

[35] Apps, P.J., Berta, M. and Prangnell, P.B. (2005) The Effect of Dispersoids on the Grain Refinement Mechanisms during Deformation of Aluminium Alloys to Ultrahigh Strains. Acta Materialia, 53, 499-511.

[36] Min, G., Lee, J.M., Kang, S.B. and Kim, H.W. (2006) Evolution of Microstructure for Multilayered Al/Ni Composites by Accumulative Roll Bonding Process. Materials Letters, 60, 3255-3259.

[37] Humphreys, F.J. and Hatherly, M. (2004) Recrystallization and Related Annealing Phenomena. 2nd Edition, Elsevier Science Ltd., Pergamon.

[38] Jamaati, R. and Toroghinejad, M.R. (2014) Effect of Stacking Fault Energy on Mechanical Properties of Nanostructured FCC Materials Processed by the ARB Process. Materials Science and Engineering: A, 606, 443-450.

[39] Tamimi, S., Ketabchi, M., Parvin, N., Sanjari, M. and Lopes, A. (2014) Accumulative Roll Bonding of Pure Copper and IF Steel. International Journal of Metals, 9, Article ID: 179723. https://doi.org/10.1155/2014/179723

[40] Kamali, M.R., Amirkhanlou, S. and Khorsand, Sh. (2014) Cross Accumulative Roll Bonding a Novel Mechanical Technique for Significant Improvement of Stir Cast $\mathrm{Al} / \mathrm{Al}_{2} \mathrm{O}_{3}$ Nanocomposite Properties. Materials Science and Engineering. A, 591, 144-149.

[41] Viswanathan, V., Laha, T., Balani, K., Agarwal, A. and Seal, S. (2006) Challenges and Advances in Nanocomposite Processing Techniques. Materials Science and Engineering. $R, 54,121-285$.

[42] Jamaati, R., Toroghinejad, M.R. and Edris, H. (2014) Effect of SiC Nanoparticles on the Mechanical Properties of Steel Based Nanocomposite Produced by Accumulative Roll Bonding. Materials and Design, 54, 168-173.

[43] Jamaati, R., Toroghinejad, M.R., Edris, H. and Salmani, M.R. (2014) Comparison of Microparticles and Nanoparticles Effects on the Microstructure and Mechanical Properties of Steel Based Composite and Nanocomposite Fabricated via Accumulative Roll Bonding Process. Materials and Design, 56, 359-367.

[44] Alizadeh, M., Paydar, M.H. and SharifianJazi, F. (2013) Structural Evaluation and Mechanical Properties of Nanostructured Al/B4C Composite Fabricated by ARB. Composites: Part B, 44, 339-343.

[45] Reihanian, M., Keshavarz, H.F. and Paydar, M.H. (2014) Fabrication of Al-2vol\% $\mathrm{Al}_{2} \mathrm{O}_{3} / \mathrm{SiC}$ Hybrid Composite via Accumulative Roll Bonding (ARB): An Investigation of the Microstructure and Mechanical Properties. Materials Science and Engineering: $A, 607,188-196$.

[46] Karbasi, M. and Alamdari, E.K. (2015) Investigation of Lead Base Composite Anodes Produced by Accumulative Roll Bonding. Materials and Design, 67, 118129.

[47] Naseri, M., Reihanian, M. and Borhani, E. (2016) Bonding Behavior during Cold Roll Cladding of Tri-Layered Al/Brass/Al Composite. Journal of Manufacturing Processes, 24, 125-137. 
Submit or recommend next manuscript to SCIRP and we will provide best service for you:

Accepting pre-submission inquiries through Email, Facebook, LinkedIn, Twitter, etc. A wide selection of journals (inclusive of 9 subjects, more than 200 journals)

Providing 24-hour high-quality service

User-friendly online submission system

Fair and swift peer-review system

Efficient typesetting and proofreading procedure

Display of the result of downloads and visits, as well as the number of cited articles Maximum dissemination of your research work

Submit your manuscript at: http://papersubmission.scirp.org/

Or contact ojmental@scirp.org 